\title{
Influences of Peptide Side Chains on the Metal \\ Ion Binding Site in Metal Ion-Cationized \\ Peptides: Participation of Aromatic Rings in Metal Chelation
}

\author{
Peifeng $\mathrm{Hu}$ and Curt Sorensen \\ Midwest Center for Mass Spectrometry, Department of Chemistry, University of Nebraska-Lincoln, Lincoln, \\ Nebraska, USA
}

Michael L. Gross

Department of Chemistry, Washington University, St. Louis, Missouri, USA

\begin{abstract}
Aromatic side chains on amino acids influence the fragmentations of cationic complexes of doubly charged metal ions and singly deprotonated peptides. The metal ion interacts with an aromatic side chain and binds to adjacent amide nitrogens. When fragmentation occurs, this bonding leads to the formation of abundant metal-containing a-type ions by reactions that occur at the sites of amino acids that contain the aromatic side chain. Furthermore, formation of metal-containing immonium ions of the amino acids that contain the aromatic side chain also are formed. The abundant a-type ions may be useful in interpretation strategies in which it is necessary to locate in a peptide the position of an amino acid that bears an aromatic side chain. (I Am Soc Mass Spectrom 1995, 6, 1079-1085)
\end{abstract}

$\mathrm{T}$ The 20 common amino acids have distinctive side chains, which vary in size, shape, charge, hydrogen-bonding capacity, and chemical reactivity. It is this diversity that enables proteins to form intricate three-dimensional structures and carry out biological processes. Amino acids with functionalized side chains are especially important because these amino acids play important roles in the active sites of enzymes. They participate in the enzymatic action either directly or indirectly by maintaining the necessary conformation of the protein. The aromatic amino acids, phenylalanine, tryptophan, histidine, and tyrosine, when involved in enzymatic processes, can be a part of hydrophobic interactions, which are often important for specificity [1].

In solution, transition metal ions $\mathrm{CCu}^{2+}, \mathrm{Pd}^{2+}$, and $\mathrm{Ni}^{2+}$ ) interact with peptides that contain aromatic side chains and even aliphatic side chains [2]. Tripeptides readily form a square planar complex in which the C-terminal carboxylate, two deprotonated amide nitrogens, and the $\mathrm{N}$-terminal amine group are bound to the metal ion. Bulky side chains (e.g., those of phenylalanine, tyrosine, tryptophan, leucine, and isoleucine, etc.) are situated over the chelation ring so they may interact with the metal ion $[2,3]$. An example is the

Address reprint requests to Professor Michael L. Gross, Department of Chemistry, Washington University, I Brookings Drive, St. Louis, MO 63130 . high population of the rotamer (1) of Gly-Leu-Tyr, which has the tyrosine side chain over the chelation ring, although conformationally this rotamer is not the most stable. Dipeptides [4-6] form a similar complex except one of the metal binding sites is occupied by a solvent molecule.

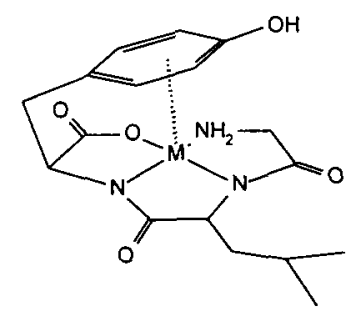

Structure 1

In crystal structures, metal ion-side chain contacts are found in dimeric or bis(peptide) complexes [7-10]. For the dimeric copper (II) chelate of Gly-Leu-Tyr and bis(tyrosinato) copper (II), the aromatic ring was found to be within bonding distance of the metal in the crystal [7-10]. On the basis of these observations, it was suggested that an interaction of this nature explains the activity of certain copper-containing oxidases $[3,10]$. A metal ion-side chain interaction, however, was not found in the crystal of copper (II) chelate of Leu-Tyr $[11,12]$. 
Metal cation- $\pi$-electron interactions recently have been the focus of both theoretical and experimental investigations [13-15]. These studies shed new light on the mechanisms of enzyme-ligand binding interactions. For example, a recent model to explain the binding sites for choline and its derivatives has as its basis the interaction between the trimethylammonium end of acetylcholine ( $\mathrm{Ach}$ ) and the aromatic amino acids (Phe, Tyr, and Trp). These interactions may play a critical role in the binding of Ach to its receptor, whereas interactions with anionic residues in the binding site may play a secondary role [14]. This model has received considerable support from studies of the crystal structure of the Ach esterase [16]. In addition, interactions between potassium ions and aromatic rings were proposed to be involved in the establishment of metal ion selectivity [15]. Experiments with model systems show this type of interaction to be strong [13-15]. Even $\varepsilon$-methylene hydrogens of a lysine [17] can interact with $\pi$-electrons of aromatic ring. As a model for aromatic ring-hydrophilic interactions, it was recently demonstrated that benzene forms hydrogen bonds with water [18].

Metal ion- $\pi$-electron interactions also were reported for species in the gas phase $[19,20]$. Transition metal- $\pi$-electron complexes also were examined by using electron ionization mass spectrometry [21].

In previous studies [22-24], we reported facile losses of certain peptide side chains from anionic complexes of alkaline-earth and transition metal ions in the gas phase. This chemistry results from metal ion-side chain interactions. The loss of a side chain does not usually occur readily when protonated or alkali metal ion-peptide adducts that are positively charged are subjected to collisional activation. In this article, however, we show that the side chains of aromatic amino acids interact with the doubly charged metal ion in metal-cationized peptide complexes that bear a positive charge. The chemistry was characterized by investigation of various peptides interacting with $\mathrm{Ca}^{2+}, \mathrm{Sr}^{2}$, $\mathrm{Ba}^{2+}, \mathrm{Mn}^{2+}, \mathrm{Fe}^{2+}, \mathrm{Co}^{2+}$, and $\mathrm{Ni}^{2+}$.

It is an honor to dedicate this paper to Professor Fred W. McLafferty, who was the first to show the senior author the joys of the use of mass spectrometry to investigate the structures and properties of gas-phase ions. We believe that mass spectrometry has much to contribute to the understanding of intrinsic properties of biological molecules in the gas phase such as those of peptide and metal ion complexes.

\section{Results and Discussion}

The collision-activated decompositions of alkalineearth metal-cationized peptides demonstrate that the positively charged complexes have a composite structure in which the contributing structures have a metal ion bound at different amide groups [25]. An amino acid that bears a basic side chain directs the fragmentation so that cleavages in its immediate proximity be- come favorable. No influence of an aromatic amino acid on the fragmentation was seen even though all the peptides investigated contain phenylalanine or tyrosine. However, we report here that amino acids that have aromatic side chains influence the decompositions of doubly charged metal ion-cationized peptides. The influences are particularly strong for the complexes of transition metal ions $\left(\mathrm{Co}^{2+}, \mathrm{Ni}^{2}, \mathrm{Fe}^{2}\right.$, and $\mathrm{Mn}^{2+}$ ) that are reported here. For complexes of alkaline-earth metal ions $\left(\mathrm{Ca}^{2+}, \mathrm{Sr}^{2+}\right.$, and $\left.\mathrm{Ba}^{2+}\right)$, the influence of an aromatic residue is significant for tri- and tetrapeptides, but not for larger peptides.

\section{Collision-Activated Decompositions of Metal Ion-Cationized Peptides that Contain Phenylalanine and Tyrosine}

The prominent decompositions of the complexes of phenylalanine- or tyrosine-containing peptides are the formation of the metal-bound a-type ions at the sites of phenylalanine or tyrosine and of metal-bound immonium ions of tyrosine or phenylalanine. The structures of the ions will be discussed later. The decompositions occur for peptides of different size (Figure 1) and sequence (Figure 2). The $\mathrm{Co}^{2+}$-immonium ion of tyrosine and the $\left[\mathrm{a}_{n}-\mathrm{H}\right]^{\prime}$ are the two most abundant ions for the tyrosine-containing peptides (Figure 1). For the isomeric pentapeptides that contain four alanines and one phenylalanine, the $\left[\mathrm{a}_{n}-\mathrm{H}\right]^{+}$ions along with metal-containing immonium ions of phenylalanine are the most abundant. Metal-containing dipeptide immonium ions (e.g., $\mathrm{Co}^{2+}-$ Phe-Ala) also form. If the peptide contains two phenylalanines or two tyrosines or one of each (Figure 3), abundant $\left[\mathrm{a}_{n}-\mathrm{H}\right]^{+}$ions, in addition to metal-bound immonium ions, form via reactions at each site of an amino acid that bears the aromatic substituent.

For peptides that contain a $C$-terminal phenylalanine or tyrosine residue, the production of $\left[\mathrm{a}_{n}-\mathrm{H}\right]^{+}$ or $\left[\mathrm{a}_{n}+\mathrm{H}\right]^{+}$, where $n$ is the number of amino acids in the peptides, is usually facile. In some cases, however, the abundances of $\left[\mathrm{a}_{n-1}-\mathrm{H}\right]^{+}$ions are enhanced (e.g., the $\left[\mathrm{a}_{4}-\mathrm{H}\right]^{+}$ion for the peptide in Figure 2e). We do not understand why this exception occurs.

Metal ion dependence. The AAYAA complexes of different metal ions $\mathrm{CCa}^{2+}, \mathrm{Sr}^{2+}, \mathrm{Ba}^{2+}, \mathrm{Mn}^{2+}, \mathrm{Fe}^{2+}, \mathrm{Co}^{2+}$, and $\mathrm{Ni}^{2+}$ ) were studied to establish the effect of the complexing metal ion. The immonium and $\left[\mathrm{a}_{n}-\mathrm{H}\right]^{+}$ ions are the dominant products formed in the fragmentations of $\mathrm{Ni}^{2+}$ and $\mathrm{Co}^{2+}$ (Figure 1c) complexes, whereas these ions are only two of many abundant ions formed from $\mathrm{Fe}^{2+}$ and $\mathrm{Mn}^{2+}$ complexes. The

\footnotetext{
To keep nomenclature for fragment ions simple, the precursor ion is treated as if it were a protonated peptide. If a reaction produces an $a_{n}^{+}$ion for a protonated peptide, it produces an $\left[a_{n}-H\right]^{*}$, where a is $\left[\mathrm{a}_{\|}-\mathrm{H}+\mathrm{Met}\right]^{+}$, for the metal-cationized peptide. The $\left[\mathrm{a}_{\|}-\mathrm{H}\right]{ }^{\prime}$ is formed by one proton transfer to the departing neutral, which motivates the use of the "-H" designation. The subscript $"$ is defined as usual.
} 


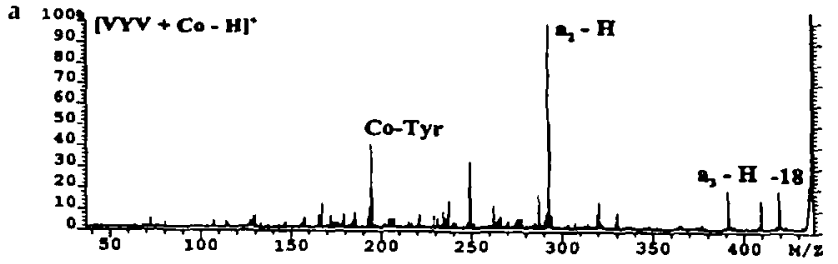

b 1

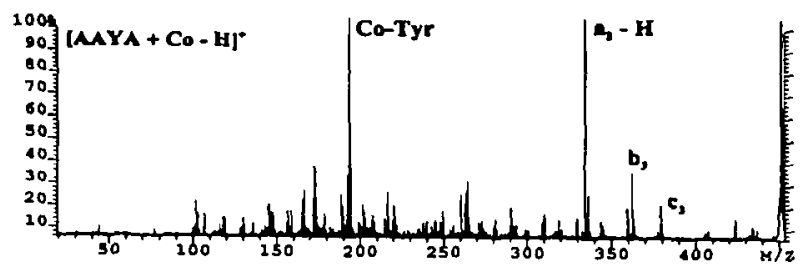

C 1

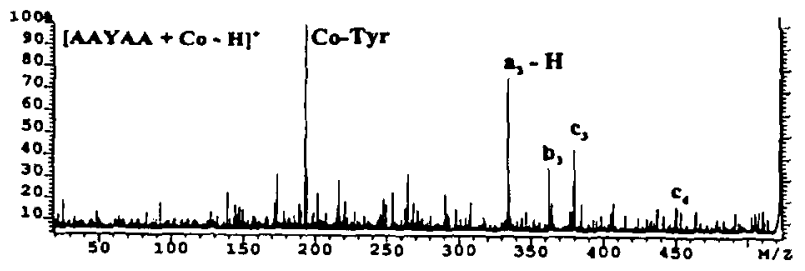

d 100

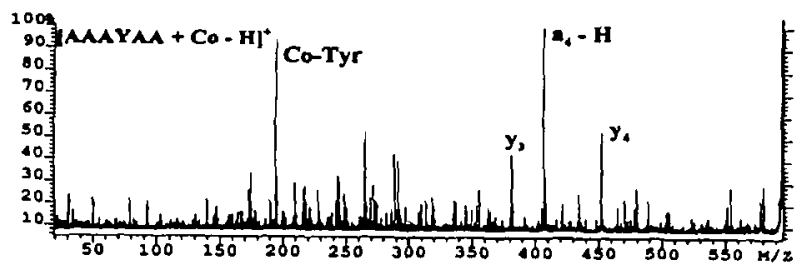

Figure 1. The CAD spectra of $\mathrm{CO}^{3+}$-cationized (a) VYV, (b) AAYA, (c) AAYAA, and (d) AAAYAA.

immonium ion at the tyrosine site is not produced, and the $\left[\mathrm{a}_{1}-\mathrm{H}\right]^{+}$ion is not a dominant product for complexes of alkaline earth metal ions.

Although amino acids that bear aromatic side chains have little effect on the fragmentation of alkaline-earth metal complexes of penta- or hexapeptides, they do

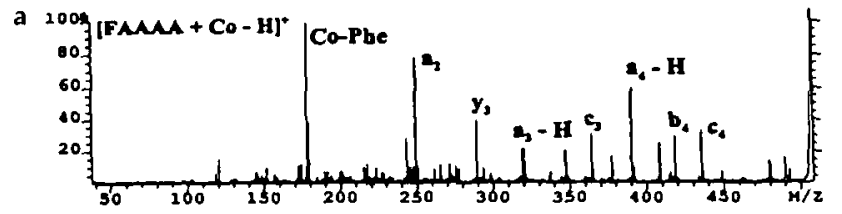

b 100

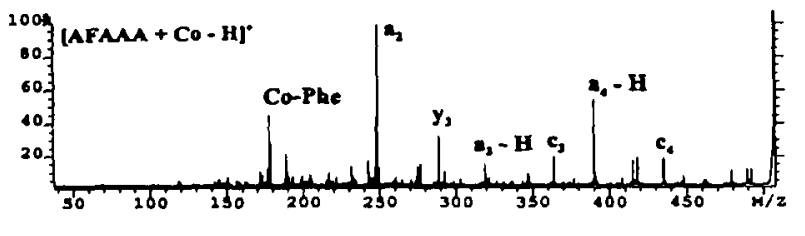

C $100 \mathrm{~g}$

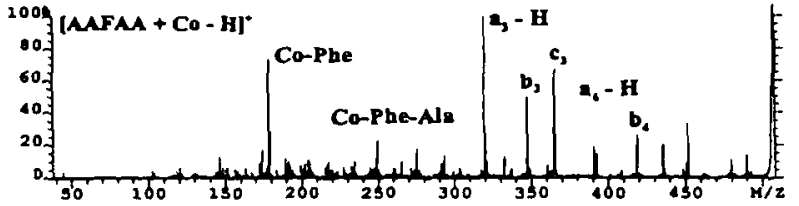

d 200

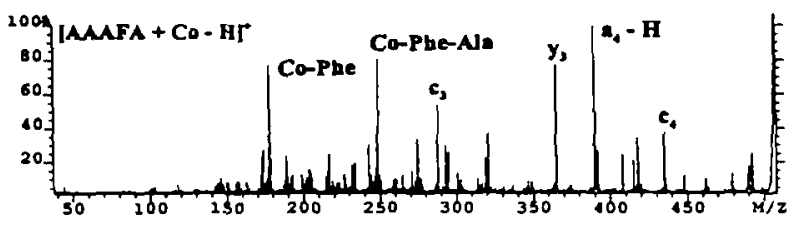

e 100

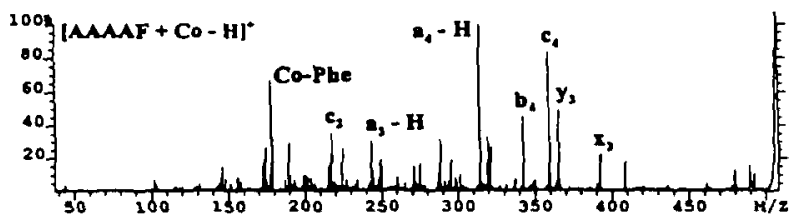

Figure 2. The CAD spectra of $\mathrm{Co}^{2+}$-cationized (a) FAAAA, (b) AFAAA, (c) AAFAA, (d) AAAFA, and (e) AAAAF.

influence significantly the collision-activated decompositions of smaller peptide complexes. As shown in Figure 4 , the $\left[\mathrm{a}_{2}-\mathrm{H}\right]^{+}$ion is produced as the most abundant species upon collisional activation of the VYV complex, and the $\left[\mathrm{a}_{3}-\mathrm{H}\right]^{+}$ion is also abundant

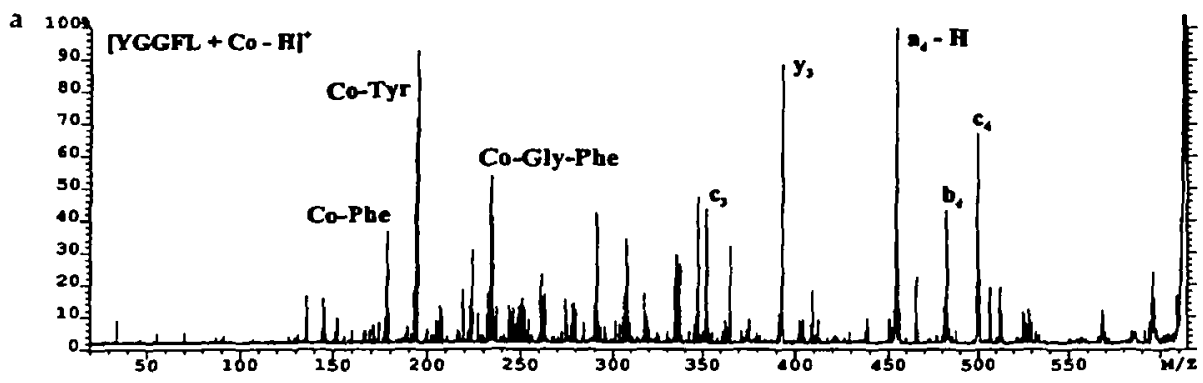

b

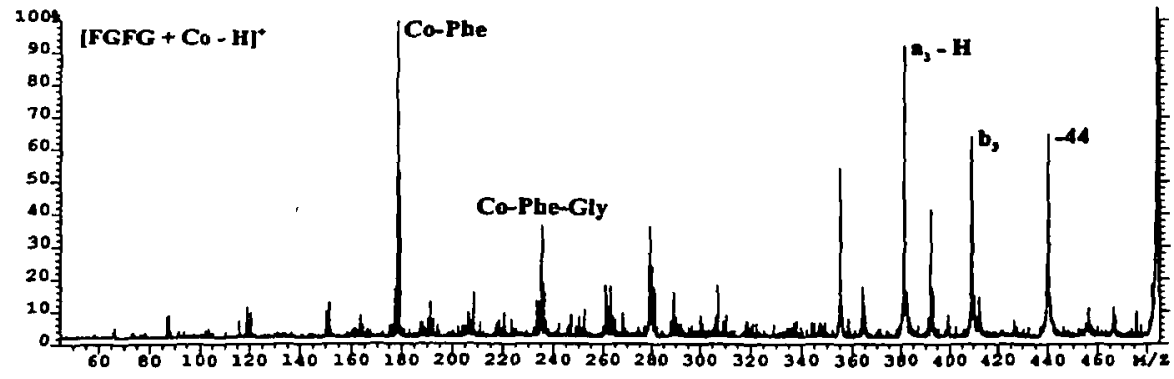

Figure 3. The CAD spectra of $\mathrm{Co}^{2+}$-cationized (a) YGGFL and (b) FGFG. 


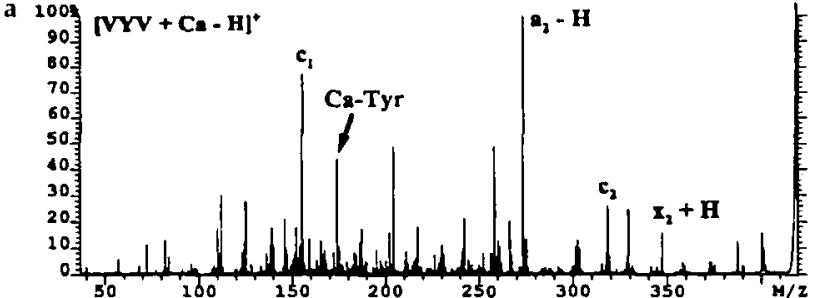

b 100
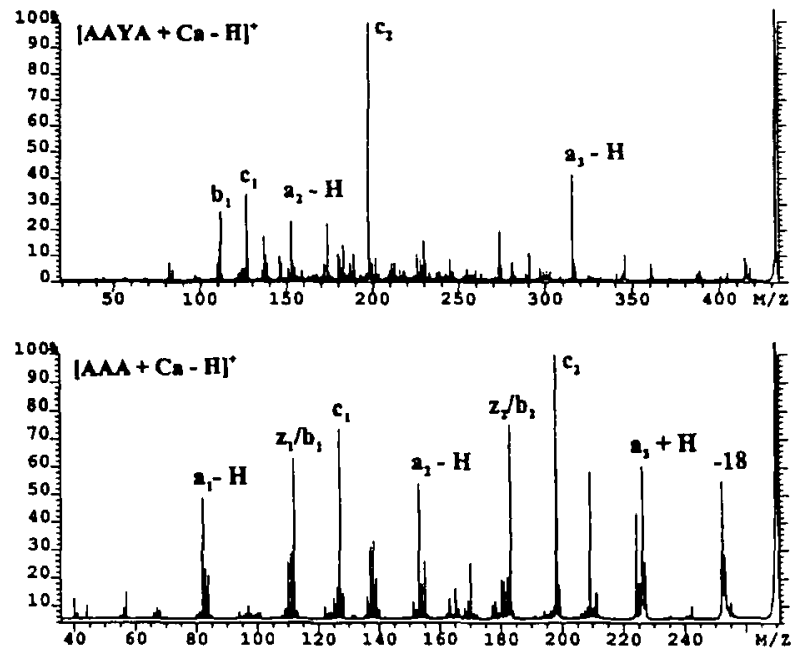

Figure 4. The CAD spectra of $C_{a^{2}}$-cationized (a) VYV, (b) $A A Y A$, and (c) AAA

for the AAYA complex. As a reference point, the fragmentation of the complex with AAA does not give an $\left[\mathrm{a}_{2}-\mathrm{H}\right]^{+}$ion of enhanced abundance. The $\mathrm{Ca}^{2+} \mathrm{com}-$ plexes of other tri- or tetrapeptides (e.g., GFA and AFAA) decompose in a similar fashion upon collisional activation.

Differences also are observed for the desorption of metal-cationized peptides with or without a constituent amino acid that bears an aromatic side chain. Peptides that contain only amino acids with aliphatic side chains are more difficult to be desorbed as a metal ion complex than those that contain one or more aromatic amino acids. In fact, peptides that bear aliphatic side chains and that are larger than tetrapeptides (e.g., pentaalanine and hexaalanine) do not undergo desorption to give any detectable [pept $\left.+\mathrm{Met}^{2+}-\mathrm{H}^{+}\right)^{+}$. On the other hand, pentapeptides and even hexapeptides that are comprised principally of alanines, but contain one tyrosine or phenylalanine, can be desorbed readily. The surface activity of metal-complexed phenylalanine or tyrosine-containing peptides may be a factor if it is large compared to that of a peptide that contains only amino acids that bear aliphatic side chains, but this is not yet established.

Aromatic ring participation in metal binding. The strong effect of amino acids that have aromatic side chains on the fragmentation of peptide complexes in which the metal ion is doubly charged should be a function of the structure of the complexes. If, as reported previously [25], amide binding is most important (see 2),
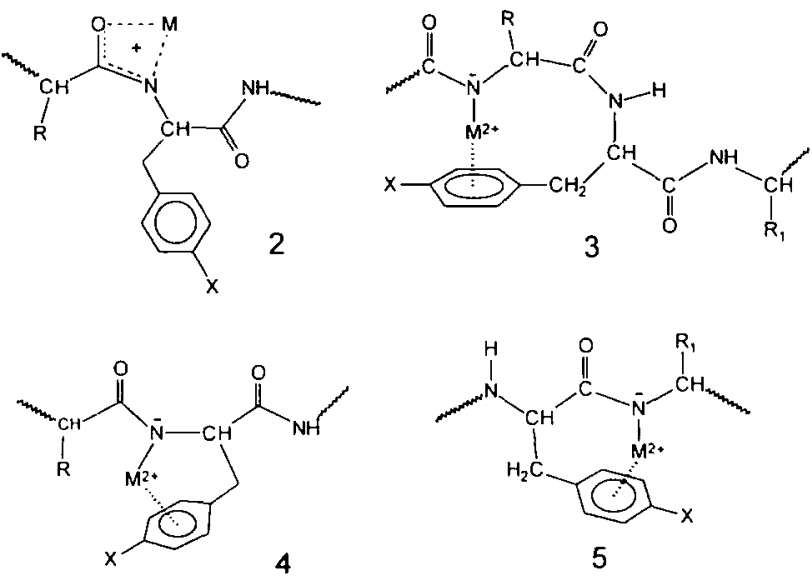

Structures 2-5

then $\left[\mathrm{a}_{n}-\mathrm{H}\right]^{+}$ion formation should not depend on the position of the amino acid that bears the aromatic side chain. Because position is important, the aromatic side chain also must play a role in the metal binding. Possible structures are 3, 4, and 5, which have the metal ion bound at the aromatic ring and at an adjacent amide nitrogen and which are probably more stable than 2. Their populations, therefore, are enhanced with respect to other structures that comprise the structure composite.

For peptides that contain two amino acids with aromatic side chains, the metal ion primarily binds at these rings and with adjacent amide nitrogens. These structures then produce appropriate $\left[\mathrm{a}_{n}-\mathrm{H}\right]^{+}$ions and also two immonium ions that exhibit bonding between the metal ion and the phenylalanine site or the tyrosine site (see Figure 3 ).

The hydroxyl group of tyrosine is unlikely to be involved in metal coordination if the metal binds to the deprotonated amide nitrogens in structures 4 and 5. Given that both the hydroxyl oxygen and the methylene group on the para position of the benzene ring must be coplanar, the bonding distance between the metal and the oxygen would be greater than $5 \AA$, which is an impractical bond length (see Structure 6). Therefore, tyrosine is proposed to coordinate to the metal ion primarily via its aromatic ring. The involvement of the hydroxyl group in the metal chelation, however, cannot be excluded for structure 3 .

The formation of $\left[\mathrm{a}_{n}-\mathrm{H}\right]^{+}$ions from alkaline-earth metal complexes was reported in a previous article [25] to require that alkaline-earth metal ions be bonded

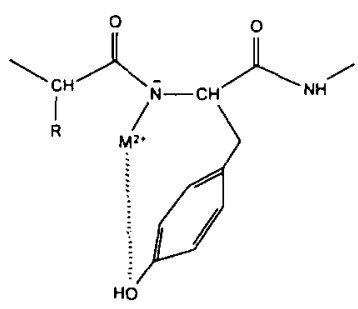

Structure 6 

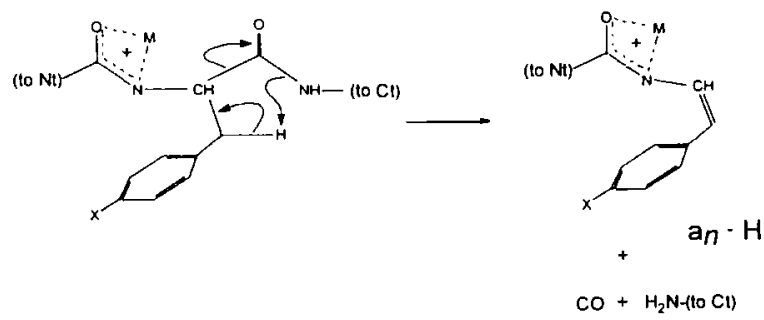

Scheme I

in close proximity to the reaction site. The metal ion polarizes bonds and thus lowers activation energies for the reactions. There are two possible mechanisms (Schemes I and II) for the production of $\left[\mathrm{a}_{n}-\mathrm{H}\right]^{+}$ ions, dependent on the source of the transferred hydrogen [25]. One mechanism involves the rearrangement of a beta hydrogen (Scheme I), whereas the other includes transfer of an amide hydrogen (Scheme II).

Replacement of all active hydrogens by deuterium enables us to see that complexes of alkaline-earth metal ions form $\left[\mathrm{a}_{n}-\mathrm{H}\right]^{+}$ions at sites of amino acids that contain aromatic residues by transfer of a nonamide hydrogen to the incipient neutral, whereas complexes of transition metal ions react by transfer of an amide hydrogen. This difference reflects the fundamental properties of the two classes of metal ions Alkalineearth metal ions may interact only weakly with aromatic rings, and the metal ion primarily binds to amide groups as is depicted in structure 2 . The $\left[\mathrm{a}_{11}-\mathrm{H}\right]$ cations are produced via the mechanism in Scheme I. The mechanism in Scheme II does not occur in this case, probably because the product is not as stable as that formed by the mechanism in Scheme l. The enhanced abundance of the $\left[\mathrm{a}_{n}-\mathrm{H}\right]^{+}$ions that are produced at sites of aromatic residues in alkalineearth-metal-ion complexes of small peptides (Figure 4) may be due to a probability argument; that is, there are few interactions of the type shown in Scheme 1 for a small peptide, and those with the aromatic ring are now relatively more important.

For complexes of transition metal ions, the metal ion interacts with the aromatic rings, and structures 3 , 4 , and 5 are likely to be major contributors to the composite structure. Of these, structures 3 and 4 are possible precursors for the $\left[\mathrm{a}_{n}-\mathrm{H}\right]$ cations. However, they do not support $\left[\mathrm{a}_{n}-\mathrm{H}\right]^{+}$ion formation by the mechanism shown in Scheme I because the $\mathrm{H}$ transfer shown in that scheme is not in accord with the deuterium labeling results. The mechanism in Scheme II is ruled out because there is no special contribution by the aromatic ring located on the side chain.

An alternative mechanism (Scheme III) involves structure 3 as a precursor, and the transferred hydrogen is an amide hydrogen in accord with the labeling results. Furthermore, the amide nitrogen that is bonded to the proton to be transferred also can interact with the metal ion, which enhances the acidity of that amide group. By this mechanism, the introduction of a dou-

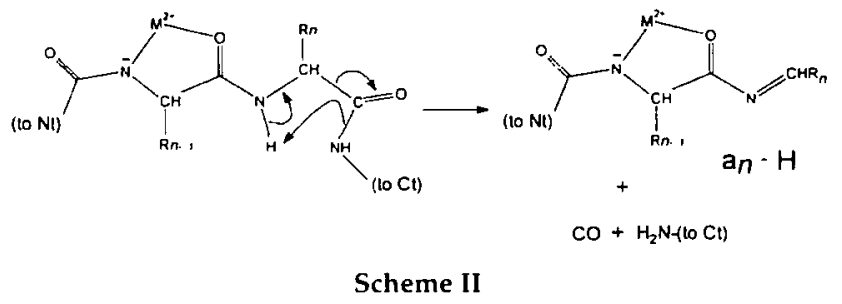

ble bond in the product adds minimal strain to the large ring that incorporates the metal bonding. Additional evidence is that both amide and nonamide hydrogens are transferred in the formation of the $\left[\mathrm{a}_{n}-\mathrm{H}\right]$ cations at sites that have non-aromatic residues no matter what type of metal ion is involved. This occurs because both alkaline-earth and transition metal ions bind only to the amide group as in structure 1 . The $\left[\mathrm{a}_{n}-\mathrm{H}\right]^{+}$ions are now produced by both mechanisms depicted in Schemes I and II.

The precursor for the immonium ions may be structure 4. Not only are closed-shell immonium ions produced, but also a radical cation, as is seen by triplet peaks, which indicate that both simple bond cleavage and cleavages accompanied by hydrogen transfers occur. The resulting products are likely to have three structures, 7 , and 9 . An ion of structure 8 (and sometimes 9 ) is the most abundant. An ion of structure 7 has not been observed to have high abundance, probably because both metal bonding and conjugation with the exocyclic double bond cannot occur.

The contribution of ions that have structure 5 to the population of fragmenting ions is usually not as important as those of ions of structures 3 and 4 . For some peptides, however, the $c_{n}$ ion abundances are enhanced.

\section{Peptides That Contain Histidine}

Histidine has a basic, nitrogen-containing side chain that also may act as a primary binding site for metal ions. This side chain can bind to metal ions via nitrogen atoms. The effects of this side chain on the structure of gas-phase metal-cationized peptides are more complicated than those of phenylalanine and tyrosine. For example, the collision-activated decompositions of $\mathrm{Ca}^{2+}$-VYIHP complex lead to formation of abundant $\left[a_{4}-H\right]$ and $\left[a_{2}-H\right]$ cations (Figure $5 b$ ), whereas the $\mathrm{CO}^{2+}$ complex decomposes to give the expected $\mathrm{Co}^{2-}$ bound immonium ions of both tyrosine and histidine,

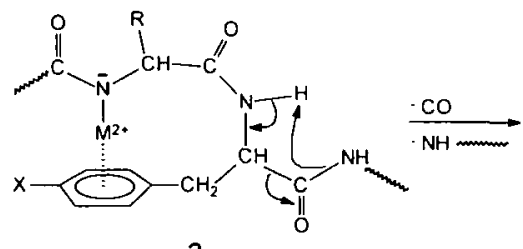

3

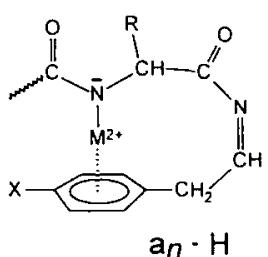

$\mathrm{a}_{n} \cdot \mathrm{H}$
Scheme III 

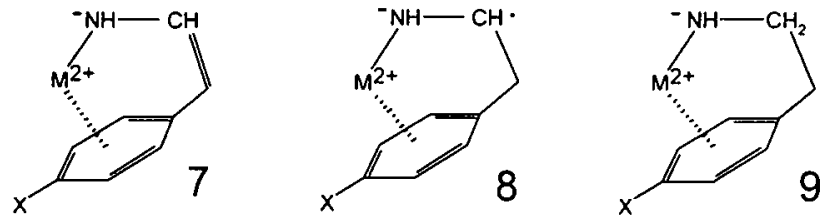

Structures 7-9

as well as the $\left[\mathrm{a}_{2}-\mathrm{H}\right]$ and $\left[\mathrm{a}_{4}-\mathrm{H}\right]$ cations (Figure $5 a)$. Although the production of the $\left[\mathrm{a}_{4}-\mathrm{H}\right]$ cation at the site of the histidine residue is favored, its formation involves more than metal-imidazole ring bonding. The metal ion also may interact with the imidazole ring via the nonbonding electrons of a ring nitrogen. This is in accord with the production of the immonium ions $\mathrm{Co}-\mathrm{IH}$ (Figure 5a) and Ca-IHP (Figure 5b).

\section{Conclusion}

For monopositive metal ion-peptide complexes that involve doubly charged metal ions, the metal ion bonds in part to the aromatic side chain of constituent amino acids and in part to anionic (deprotonated) amide groups that adjoin the site of the aromatic amino acid. Bonding of this nature promotes formation of abundant metal-containing immonium ions and $\left[\mathrm{a}_{n}-\mathrm{H}\right]$ cations at the site of the amino acid that carries the aromatic side chain. Transition metal ions, particularly $\mathrm{Co}^{2+}$ and $\mathrm{Ni}^{2+}$, have high intrinsic ability to coordinate to aromatic rings on the side chains and to promote formation of immonium and appropriate $\left[\mathrm{a}_{n}-\mathrm{H}\right]$ ions.

\section{Experimental}

\section{Materials}

The tyrosine-containing peptides (AAYA, AAAYA, AAYAA, and AAAYAA) were purchased from Bachem Bioscience Inc., a subsidiary of Bachem Switzerland
(Philadelphia, PA) Other peptides used in this work (AAA, AAAA, ALA, GGF, GGV, GFA, GFGF, GLA, FGG, FGFG, IWVN, VAAF, and VYIHP) were purchased from Sigma Chemical Co. (St. Louis, MO). The metal hydroxides and acetates were from Fisher Scientific Co. (Fair Lawn, NJ). Glycerol and thioglycerol were purchased from Aldrich Chemical Co. (Milwaukee, WI).

The phenylalanine-containing pentapeptides (FAAAA, AFAAA, AAFAA, AAAFA, AAAAF, and AFAA) were synthesized at the Protein Core Facility at the University of Nebraska. The starting materials (Fmoc-A, A-OtBu, Fmoc-AA, AA-OtBu, Fmoc-F, and $\mathrm{F}-\mathrm{OtBu}$ ) were purchased from Bachem.

\section{Instrumentation}

The mass spectrometer used for this work was a VG four-sector ZAB-T tandem instrument (VG Analytical, Manchester, UK). It consisted of two high-mass, double-focusing mass spectrometers [26]. The design of the second-stage instrument was a reverse-geometry Mattauch-Herzog-type mass spectrometer. The instrument was equipped with a $\mathrm{Cs}^{+}$gun that provided a $17-\mathrm{keV} \mathrm{Cs}^{+}$beam (the overall energy for desorption was $9 \mathrm{keV}$ ). When mass spectra were acquired, only the first-stage mass spectrometer and its intermediate detector were used. When tandem mass spectrometry experiments were conducted, ions were selected by using the first stage of the instrument at a resolving power of approximately 1500, and B/E-linked scan was taken with the second-stage mass spectrometer to acquire a mass spectrum of product ions formed by collisional activation in the collision cell located between the two stages. The object slit of the second stage was closed so that the peak of the selected ion went from flat to round-topped (slit fully illuminated) so that the resolving power used for the product ions was approximately 1000 (full width at half-maximum). The single-point detector was used.
Figure 5. The CAD spectra of (a) the $\left[\text { VYIHP }+\mathrm{Co}^{2+}-\mathrm{H}^{+}\right)^{+}$ion and (b) the $\left[\text { VYIHP }+\mathrm{Ca}^{2+}-\mathrm{H}^{+}\right)^{+}$ion.

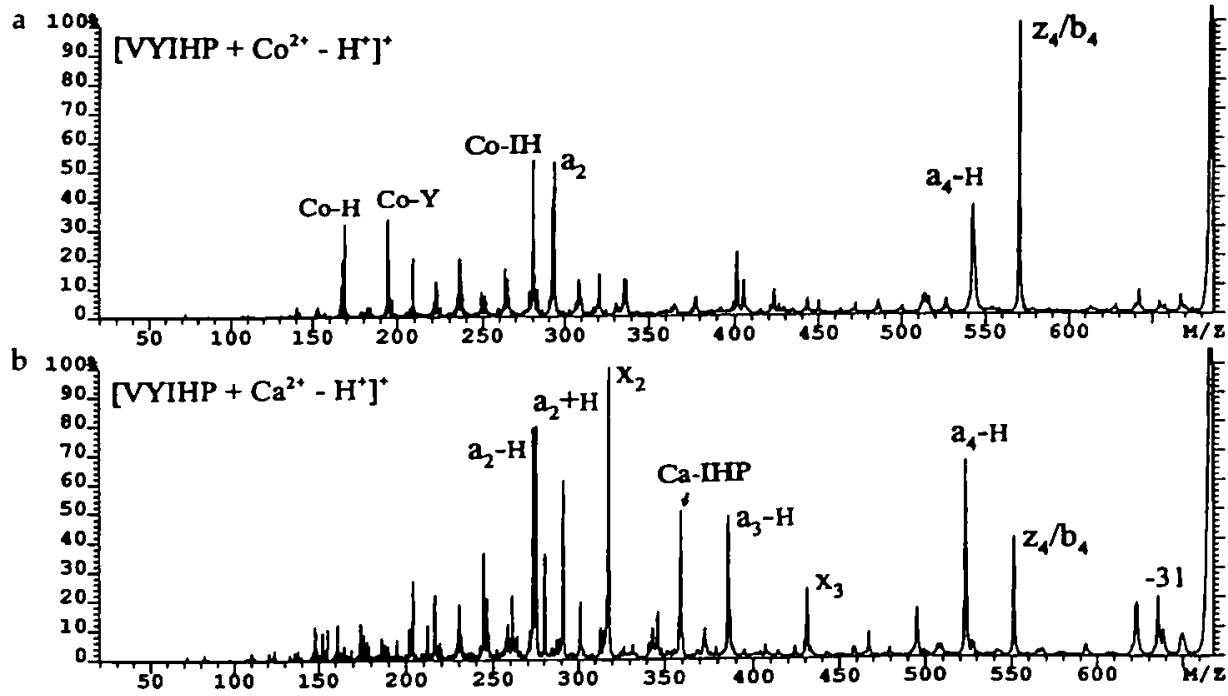




\section{Procedures}

For the mass spectrometry experiments, a few micrograms of the peptide were mixed on the fast=atom bombardment (FAB) probe tip with glycerol-thioglycerol (1:1) that was saturated with an alkaline-earth metal hydroxide or had approximately $0.5-\mathrm{F}$ metal acetate in it. For experiments with deuterium-labeled peptides, the peptide and the matrix $(\sim 1 \mu \mathrm{L})$ were mixed on the tip of the FAB probe. Approximately 1 $\mu \mathrm{L}$ of $\mathrm{D}_{2} \mathrm{O}$ was then added to the mixture, and the probe was inserted into the prevacuum system of the mass spectrometer and the volatile water $\left(\mathrm{H}_{2} \mathrm{O}, \mathrm{HDO}\right.$, and $\mathrm{D}_{2} \mathrm{O}$ ) was pumped away for a time period of 5 $\mathrm{min}$. The procedure was repeated four times. The probe was then admitted to the FAB ion source and the metal ion-peptide complexes were desorbed. The signal for the $[\mathrm{M}+\mathrm{H}]^{+}$in which all active hydrogens had been replaced was at least $90 \%$ relative to those for ions in which partial exchange had taken place.

\section{References}

1. Blow; D. M.; Steitz, T. A. Ann. Rev. Biochent. 1970, 39, 63-100.

2. Vestues, P. I:; Martin, R. B. I. Am. Chem. Soc. 1980, 102, 7906-7909.

3. Kozlowski, H. Inorg. Chim. Actn 1978, 31, 135-140.

4. Kozlowski, H., Jezowska, B., Szyszuk, H. I. Mol. Struct. 1978, $50,73-80$.

5. Kozlowski, H.; Formicka-Kozlowska, G.; Jezowska-Trzebiatowska, B. Org. Magnt. Res. 1977, 10, 146-150.
6. Kozlowski, H.; Jezowska, M. Chemt. Phys. Lett. 1977, 47.. $452-456$.

7. Sarat, M.; Jesowska, M.; Kozlowski, H. Inorg. Chim. Acta $1979,37, \mathrm{~L} 511-\mathrm{L} 512$.

8. Van Der Helim, D; Tatsch, C. E. Actă Crystallogr., Sect. B $1972,28,2307-2312$.

9. Hursthouse, M. B. J. Cheni. Soc. Dalton Trans. 1971, 207.

10. Franks, W. A.; Van Der Helm, D. Acta Criystallogr, Sect. B 1971, 27, 1299-1310.

11. Van Der Helm, D; Ealick, S. E; Burks, J. E. Acta Crystallogr., Sect. B 1975, 31, 1013-1018.

12. Mosset, P. A.; Bonnet, J. J. Acta Crystallogr., Sect. B 1977, 33 , 2807-2812.

13. Caldwell, J. W.: Kollman, P. A. J. Am. Chem. Soc. 1995, 117, $4177-4178$.

14. Dougherty, D. A.; Stauffer, D. A. Science 1990, 250, 1558-1560.

15. Kumpf, R. A.; Dougherty, D. A. Science 1993, 261, 1706-1710.

16. Sussman, J. L; Harel, M.; Frolow, F; Oefner, C.; Goldman, A,; Toker, L, Silman, I. Science 1991, 253, 872-879.

17. Abraham, D. J.; Leo, A. J. Proteins Structure, Function, and Genetics 1987, 130-152.

18. Suzuki, S.; Green, P. G.; Bưmgarner, R. E; Dasgupta, S.; Goddard, W. A.; Blake, G. A. Science 1992, 258, 942-945.

19. Sunner, J.; Nishizawa, K.; Kebarle, P. J. Phis. Chem. 1981, 85,1814 .

20. Taft, R. W. Pure Appl. Chent. 1990, 62, 17.

21. Zagorevskii, D. V., Chen, H.; Holmes, J. L; Nekrasov, Y. S.; Chizhevski, I. T.; Rastova, N. V.; Kolobova, N. E. Org. Mass Spectrom. 1993, 28, 463-469.

22. Hu, P. F.; Gross, M. L. J. An. Chem. Soc. 1992, 114, 9153-9160.

23. Hu, P. F.; Gross, M. L. J. Am. Chem. Soc. 1992, 114, 9161-9169.

24. Hu, P. F; Gross, M. L. J. Am. Chem. Soc. 1993, 115, 8821-8828.

25. Teesch, L.; Adams, J. 1. Am. Chem. Soc. 1990, 112, 4110-4120.

26. Gross, M. L. Methods Enzymol. 1990, 193, 131-153. 